\title{
Dietary intake and use of dietary supplements in relation to demographic variables among pregnant Finnish women
}

\author{
Tuula Arkkola ${ }^{1 *}$, Ulla Uusitalo ${ }^{2}$, Minna Pietikäinen ${ }^{3}$, Johanna Metsälä ${ }^{3}$, Carina Kronberg-Kippilä ${ }^{2}$ \\ Maijaliisa Erkkola ${ }^{3}$, Riitta Veijola ${ }^{1}$, Mikael Knip ${ }^{4}$, Suvi M. Virtanen ${ }^{2,3,5}$ and Marja-Leena Ovaskainen ${ }^{2}$ \\ ${ }^{1}$ Department of Paediatrics, 90014 University of Oulu, Oulu, Finland \\ ${ }^{2}$ Department of Epidemiology and Chronic Disease Prevention, National Public Health Institute, Mannerheimintie 166, \\ 00300 Helsinki, Finland \\ ${ }^{3}$ Tampere School of Public Health, 33014 University of Tampere, Tampere, Finland \\ ${ }^{4}$ Hospital for Children and Adolescents, 00014 University of Helsinki, Helsinki, Finland \\ ${ }^{5}$ Research Unit, Tampere University Hospital, Tampere, Finland
}

(Received 4 January 2006 - Revised 11 July 2006 - Accepted 14 July 2006)

\begin{abstract}
Proper nutrition during pregnancy may be important for maternal health and fetal growth and development. In Finland, targeted recommendations are given to guide pregnant women in their food choice and dietary supplement use so that they may obtain adequate nutritional status and meet the increased need for nutrients. The aims of the present study were to examine food choices, nutrient intake and dietary supplement use of pregnant Finnish women in association with demographic variables. One thousand and seventy-five families were invited to a birth cohort study during 1998-9. Mothers of 797 newborns completed a validated 181-item food-frequency questionnaire from which the food and nutrient intakes were calculated. The information about supplement use was collected concerning the whole pregnancy. The results of the present study suggest that healthy food choices are rather common among pregnant Finnish women and the choices are positively correlated with age and education. Nutrient supplements were used by $85 \%$ of the women. Supplements were favoured by the older and well-educated women and by those who had normal weight before pregnancy. Of the women in the present study, $31 \%$ received vitamin A-containing supplements, although it is not recommended during pregnancy. Taking food and supplementation into account, the intake of vitamin D did not meet the dietary recommendation and folic acid intake was below recommendation in $44 \%$ of the women. Therefore there seemed to be unnecessary nutrient supplementation and at the same time lack of relevant supplementation among these pregnant women.
\end{abstract}

Pregnancy: Food choice: Nutrient intake: Dietary supplement use

Nutrition during pregnancy plays an important role in the wellbeing of the mother and the fetus, and may further influence the health of the babies at a later age (Godfrey \& Barker, 1995; Andersson, 2001). Nutrient status, for example, the status of vitamin D, $n-3$ and $n-6$ fatty acids, of the fetus and newborn child is shown to be dependent on maternal intake during pregnancy (Connor et al. 1996; Zeghoud et al. 1997). The increased nutrient requirements during pregnancy can be met through a healthy and balanced diet with modest adjustments. In Finland the maternal diet during pregnancy is recommended to include fresh vegetables, fruit, berries, wholegrain products, vegetable margarine or oil, fish (two to three times per week), and fat-free milk products (Hasunen et al. 1997). Additionally all pregnant women in Finland are recommended to use $10 \mu \mathrm{g}$ vitamin $\mathrm{D}$ supplement from October to March (Advisory Committee of Government, 1998). The requirement of $\mathrm{Fe}$ and folate increases during pregnancy as well. The Fe status of all pregnant women is clarified by well-women clinics. If the $\mathrm{Hb}$ value is lower than $110 \mathrm{~g} / \mathrm{l}$ during the first trimester of pregnancy, $50 \mathrm{mg}$ supplemented Fe is recommended. During later stage of pregnancy the cutoff level of $\mathrm{Hb}$ is $100 \mathrm{~g} / \mathrm{l}$. Folate supplementation $(400 \mu \mathrm{g})$ is recommended in women with a diet excluding fresh vegetables, fruit, berries and wholegrain products, for chronic users of certain drugs, for subjects with coeliac disease, and if the fetus is at high risk of a neural tube defect. In these cases folate supplementation is recommended from the end of contraception until the twelfth week of pregnancy. If the diet is low in milk and milk products, $500-1000 \mathrm{mg} \mathrm{Ca}$ as a supplement is recommended in Finland. If the diet of the pregnant woman is overall poor or insufficient, multivitamin supplementation excluding vitamin A is recommended. Vitamin A-containing supplements, liver and liver products are not recommended because high vitamin A intake may increase the risk of malformation and miscarriage (Hasunen et al. 1997). In Finland, women attend well-women clinic about thirteen times during pregnancy. The first visit is after conception, at the eighth to twelfth week of pregnancy. 
Only a few studies have examined food choices during pregnancy. A recent Finnish study suggests that maternal age and education are associated with the composition of the diet (Erkkola et al. 1998). Older women had higher intakes of dietary fibre and more educated women consumed more vegetables and fruits during pregnancy (Erkkola et al. 1998). During pregnancy, a larger proportion of women (70-87\%) use supplements (Erkkola et al. 1998; Ervin et al. 1999) than during other phases of life (36-39\%) (Kaartinen et al. 1997; Helakorpi et al. 1999). The most typical female supplement user seems to be a well-educated woman whose diet is close to the nutritional recommendations (Kaartinen et al. 1997; Ervin et al. 1999; Kirk et al. 1999). Also age has been suggested to be associated with higher supplement use (Timbo et al. 1994). However, age and education did not differentiate supplement users and non-users during pregnancy in an earlier Finnish study (Erkkola et al. 1998). The most used supplement during pregnancy is Fe (Timbo et al. 1994; Erkkola et al. 1998; Rogers \& Emmett, 1998; Ervin et al. 1999) followed by folic acid and vitamin D (Rogers \& Emmett, 1998; Mathews et al. 2000). In several studies the total intake of vitamin A (Ortega et al. 1994; Voyles et al. 2000), folic acid (Ortega et al. 1994; Berg et al. 2001), $\mathrm{Zn}$ and vitamin $\mathrm{B}_{12}$ (Berg et al. 2001) have exceeded the dietary recommendations due to the use of supplements. Upper safe limits are given for the daily consumption of nutrients in order to protect from the harmful symptoms of an extended intake. In Finland the upper safe limit of total vitamin A consumption is $3000 \mu \mathrm{g} / \mathrm{d}$ (Advisory Committee of Government, 2005). An average intake of vitamin A in non-pregnant Finnish women was $926 \mu \mathrm{g} / \mathrm{d}$ in 2002 (Männistö et al. 2003).

In the present study we examined food choice, nutrient intake and the use of nutrient supplements in pregnant Finnish women. We also wanted to determine whether maternal age, education level or BMI influence food consumption, nutrient intake or supplement use during pregnancy. Additionally we wanted to see if nutrient supplementation is in accordance with the recommendations.

\section{Subjects and methods}

Subjects recruited for the present study are participating in the ongoing type 1 Diabetes Prediction and Prevention (DIPP) study, a large population-based birth cohort study in Finland that started in 1996. The present study has been established to predict the development of type 1 diabetes and to search for means to prevent or delay progression to clinical type 1 diabetes. Families with an infant who carry increased genetic risk (HLA DQB $1 * 02 / * 0302$ or HLA DQB $1 * 0302 / \times ; \times \neq * 0301$ or $* 0602$ ) represent about $15 \%$ of the total population and are invited to take part in the DIPP study. Ethical approval for the present study has been obtained from the Ethical Committees of the Universities of Oulu and Tampere (Finland). The nutrition part of the Diabetes Prediction and Prevention study aims at investigating maternal nutrition during pregnancy and lactation as well as the child's nutrition in relation to the natural progression from increased genetic susceptibility to the development of $\beta$-cell autoimmunity and eventually to clinical type 1 diabetes. A 1-year birth cohort in 1998-9, 1075 families with an infant with increased genetic risk of type 1 diabetes and born in one of the two Finnish University Hospitals (Tampere and Oulu) were invited to take part in the present study. Altogether 271 pregnant women refused to participate in the study and seven women had filled out the food-frequency questionnaire (FFQ) deficiently and were therefore excluded. Complete nutrition information was received from 797 mothers (74\% of those invited), who comprised the final study population.

The diet during pregnancy was assessed using a validated FFQ (Erkkola et al. 2001), comprising a list of 181 food items. The FFQ assessed the use of foods and food groups by frequency of consumption during 1 month. The FFQ focused on past diet, i.e. on the diet during the eighth month of pregnancy, before the working mothers were supposed to be on maternity leave. Mothers received the questionnaire after delivery and it was returned and checked by a study nurse at the infant's 3-month visit to the study centre. The information about supplement use was collected concerning the whole pregnancy. The mothers received written instructions to record the dietary supplements with brand names, manufacturers of the supplements, amounts of supplements per d, week or month and the month of pregnancy during which the supplements were used. All kinds of dietary supplements which were used as a source of vitamins and minerals, including multivitamins and herbal products, were taken into account. Information on maternal age, education, and weight and height at the first visit in the maternity clinic was also collected. The food consumption data were entered into a dietary database by a software program of the National Public Health Institute and an in-house program was used to calculate daily nutrient intakes. Intakes of energy, protein, total fat, saturated fatty acids, MUFA, PUFA, $n-3$ fatty acids, $n$ - 6 fatty acids, essential fatty acids (linoleic and $\alpha$-linoleic acid), carbohydrates, dietary fibre, vitamins $\mathrm{A}, \mathrm{D}, \mathrm{E}$ and $\mathrm{C}$, folic acid, $\mathrm{Ca}, \mathrm{Fe}$ and $\mathrm{Zn}$ were assessed. Information on dietary supplements was obtained from the Finnish pharmacopoeia. Information on dietary supplements other than drugs was obtained from the National Food Administration and from the manufacturers. From the supplements, the intakes of vitamin A, D, E and C, folic acid, $\mathrm{Ca}, \mathrm{Fe}$ and $\mathrm{Zn}$ were calculated.

\section{Statistical analysis}

Statistical analysis was carried out with the SPSS for Windows 12.0 program (SPSS Inc., Chicago, IL, USA). The $\chi^{2}$ test was used to evaluate the relationships between age, education, BMI, smoking status and earlier pregnancies, and supplement use or food consumption habits. ANOVA was used to evaluate the relationships between energy and nutrient intake and the maternal education level. Differences were considered significant at a two-sided $P<0 \cdot 05$.

\section{Results}

\section{Characteristics of subjects}

The mean age of the pregnant women was 29.6 (SD 5.1) years. Nutrient supplement use was more common among older, more educated, leaner and non-smoking women (Table 1). The number of earlier pregnancies did not affect supplement use. 
Table 1. Characteristics of the study population

\begin{tabular}{|c|c|c|c|c|c|c|c|}
\hline & \multicolumn{2}{|c|}{$\begin{array}{c}\text { All women } \\
(n \text { 804) }\end{array}$} & \multicolumn{2}{|c|}{$\begin{array}{l}\text { Supplement users } \\
\qquad(n 681)\end{array}$} & \multicolumn{2}{|c|}{$\begin{array}{c}\text { Non-supplement } \\
\text { users }(n 123)\end{array}$} & \multirow[b]{2}{*}{$P^{*}$} \\
\hline & $n$ & $\%$ & $n$ & $\%$ & $n$ & $\%$ & \\
\hline Age (years) & & & & & & & 0.034 \\
\hline$<25$ & 141 & 17 & 112 & 16 & 29 & 24 & \\
\hline $25-29$ & 278 & 35 & 231 & 34 & 47 & 38 & \\
\hline$\geq 30$ & 368 & 46 & 324 & 48 & 44 & 36 & \\
\hline Missing data & 17 & 2 & 14 & 2 & 3 & 2 & \\
\hline Basic education & & & & & & & 0.018 \\
\hline Less than high school & 350 & 44 & 285 & 42 & 65 & 53 & \\
\hline High-school degree & 426 & 53 & 373 & 55 & 53 & 43 & \\
\hline Missing data & 28 & 3 & 23 & 3 & 5 & 4 & \\
\hline $\mathrm{BMI}\left(\mathrm{kg} / \mathrm{m}^{2}\right) \dagger$ & & & & & & & 0.003 \\
\hline$<25$ & 502 & 63 & 445 & 65 & 57 & 46 & \\
\hline $25-29$ & 196 & 24 & 163 & 24 & 33 & 27 & \\
\hline$\geq 30$ & 67 & 8 & 50 & 7 & 17 & 14 & \\
\hline Missing data & 39 & 5 & 23 & 4 & 16 & 13 & \\
\hline Smoking during pregnancy & & & & & & & $<0.01$ \\
\hline No & 682 & 85 & 599 & 88 & 83 & 67 & \\
\hline Yes & 77 & 9 & 53 & 8 & 24 & 20 & \\
\hline Missing data & 45 & 6 & 29 & 4 & 16 & 13 & \\
\hline Earlier pregnancies & & & & & & & 0.250 \\
\hline 0 & 324 & 40 & 278 & 41 & 46 & 38 & \\
\hline 1 & 258 & 32 & 211 & 31 & 47 & 38 & \\
\hline 2 or more & 192 & 24 & 167 & 25 & 25 & 20 & \\
\hline Missing data & 30 & 4 & 25 & 3 & 5 & 4 & \\
\hline
\end{tabular}

\section{Dietary habits}

The proportion of women consuming daily or weekly selected food items and food groups is shown by age, education and dietary supplement use in Table 2. About $30 \%$ of the women above 30 years or with a high-school degree consumed the daily recommended portions of vegetables, fruits and berries. The respective proportions were $16 \%$ both among the youngest and among the women with lower education. Consumption of fish and poultry was also more common among older and more educated women. Daily consumption of fruits and berries and weekly consumption of fish were more common among those women who used dietary supplements during pregnancy. Daily consumption of low-fat milk products was more common among women with a high-school degree and among non-supplement users (Table 2).

\section{Nutrient intakes}

Most of the women (85\%) complemented their diet with some nutrient supplements during pregnancy. The most common nutrient received from the supplements was Fe $(78 \%)$, followed by vitamin D (40\%) and folic acid (39\%) (Table 3). Of the women, $31 \%$ received vitamin A supplementation, but only two women took vitamin A from a single-nutrient supplement. $\mathrm{Fe}$ and $\mathrm{Ca}$ were most commonly used as a single-nutrient supplement (Table 3 ). Intake of vitamins and minerals from food and supplements is seen in Table 4. The upper limit of safe intake was exceeded only with supplemental Fe. The upper safety limit of $\mathrm{Fe}$ intake $(60 \mathrm{mg})$ was exceeded in 286 women; sixteen of the women took supplemental Fe over $250 \mathrm{mg}$. Of all the women, $85 \%$ had total vitamin $\mathrm{D}$ intake below recommendation. The total folic acid intake was below recommendation in $44 \%$ of the women (Table 4). On average, protein provided $16 \%$, carbohydrate $47 \%$ and fat $36 \%$ of the total energy intake in the diet of the pregnant women studied. Saturated fatty acids provided $15 \%$, MUFA $11 \%$ and PUFA $4 \%$ of the total energy intake. The mean intake of dietary fibre was $27.4 \mathrm{~g}$. Women under 25 years received less energy $(P=0.032)$, and their energy-adjusted intakes of protein $(P=0.004)$ and dietary fibre $(P<0.001)$ were smaller and the intake of sugar higher $(P=0.019)$ than the intakes of older women. Higher basic education was associated with a higher energy-adjusted intake of carbohydrates, dietary fibre, and n-6 fatty acids and lower intakes of total fat and saturated fatty acids (Table 5).

On average women received adequate amounts of the examined vitamins and minerals from food with an exception of vitamin D. Even the total intake of vitamin D (intake from food and supplements) in the supplement users did not meet the dietary recommendation (Fig. 1). Women who were younger than 25 years had lower intakes of vitamin $\mathrm{D}$, vitamin E, folate, $\mathrm{Fe}, \mathrm{Mg}$ (for all nutrients $P<0.001$ ) and $\mathrm{Zn}$ $(P=0.004)$ than older women. Higher basic education was associated with higher intakes of vitamin $\mathrm{D}$, vitamin $\mathrm{E}$ (both $P<0.001)$ and $\mathrm{Fe}(P=0.041)$ from food.

\section{Discussion}

Nutrient supplements are supposed to be consumed by pregnant women to support their diet. However, the present study revealed that the use of nutrient supplements did not always improve the nutrient intake. Some nutrients were received cumulatively and in large amounts from different 


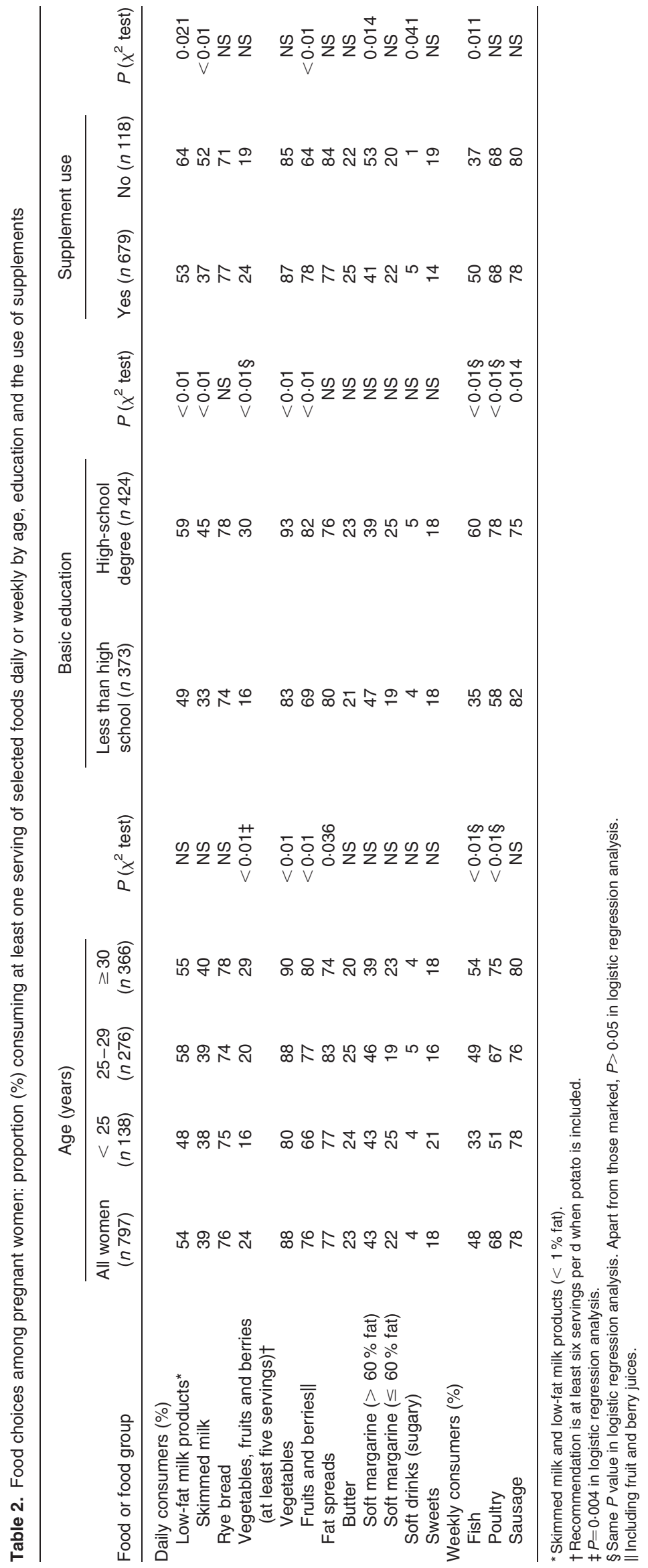


Table 3. Number and proportion of all women ( $n$ 804) who received each respective nutrient from supplements and the type of supplement used

\begin{tabular}{|c|c|c|c|c|c|c|}
\hline \multirow[b]{3}{*}{ Nutrient } & \multirow{2}{*}{\multicolumn{2}{|c|}{$\begin{array}{c}\text { Nutrient } \\
\text { users }^{*}\end{array}$}} & \multicolumn{4}{|c|}{ Type of supplement } \\
\hline & & & \multicolumn{2}{|c|}{ Single nutrient } & \multicolumn{2}{|c|}{ Multivitamin } \\
\hline & $n$ & $\%$ & $n$ & $\%$ & $n$ & $\%$ \\
\hline Vitamin A & 247 & 31 & 2 & $0 \cdot 2$ & 245 & 31 \\
\hline Vitamin D & 325 & 40 & 21 & 3 & 304 & 37 \\
\hline Vitamin E & 300 & 37 & 6 & 7 & 294 & 30 \\
\hline Vitamin C & 230 & 29 & 31 & 4 & 199 & 25 \\
\hline Folic acid & 316 & 39 & 37 & 5 & 279 & 34 \\
\hline $\mathrm{Fe}$ & 623 & 78 & 547 & 68 & 76 & 10 \\
\hline $\mathrm{Ca}$ & 123 & 15 & 84 & 10 & 39 & 5 \\
\hline
\end{tabular}

* Of the women studied, $123(15 \%)$ did not use supplements.

supplements and at the same time some relevant supplementation was missing.

In the present study $85 \%$ of the women used at least one dietary supplement. This proportion parallels the results from the earlier studies in Finnish pregnant women where $67 \%$ (Kara, 1978) and $70 \%$ (Erkkola et al. 1998) of the pregnant women reported use of at least one dietary supplement. Prevalence is higher than $36 \%$ that has been found in nonpregnant Finnish women (Kaartinen et al. 1997). Of the women, $35 \%$ had used single-Fe supplementation whereas Fe with some other supplement was used by $49 \%$ of the women. Vitamin D and folic acid were the next common supplements used. Fe has been the most common nutrient gained from supplements also in the previous studies (Erkkola et al. 1998; Rogers \& Emmett, 1998; Mathews et al. 2000) followed by folic acid and vitamin D (Rogers \& Emmett, 1998; Mathews et al. 2000). The use of nutrient supplements was associated with age, education and BMI. Supplements were used mostly by the oldest age group, by the most educated women and by those women who had normal weight before pregnancy. Also in Britain, an association between maternal age and supplement use during pregnancy has been observed (Mathews et al. 2000), as in the present study.

Although vitamin D supplementation is recommended to all pregnant women during wintertime, only $40 \%$ of the women studied had used vitamin D supplements during pregnancy and only $15 \%$ of all women had an intake of at least $10 \mu \mathrm{g} / \mathrm{d}$, as recommended. This is surprising because the data covered the whole year, also the wintertime. One reason for the low compliance with vitamin D supplementation might be inadequate counselling. In an earlier study related to dietary and health counselling in well-women clinics in Finland, only $60 \%$ of the nurses had given advice to use vitamin D supplements (Piirainen et al. 2004). The use of vitamin A-containing supplements was surprisingly common in the present study. Vitamin A was received mostly in multivitamin supplements; only two mothers used it as a single-nutrient supplement. Of all women, $31 \%$ received vitamin A from supplements, although vitamin A supplementation is not recommended during pregnancy (Hasunen et al. 1997). However, the highest vitamin A intake from supplements remained clearly lower than the highest acceptable daily intake during pregnancy $(3000 \mu \mathrm{g}$; Nordic Working Group on Diet and Nutrition, 1996).

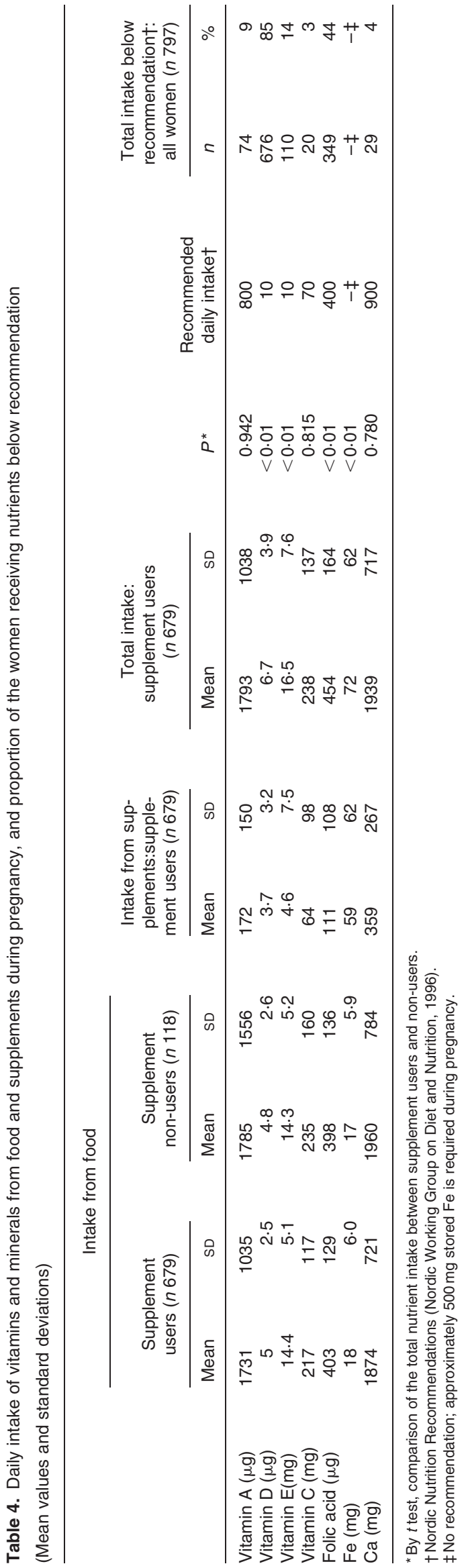


Table 5. Mean daily intake of energy-yielding nutrients, vitamins and minerals from food during pregnancy by basic education level

(Mean values and standard deviations)

\begin{tabular}{|c|c|c|c|c|c|}
\hline \multirow[b]{3}{*}{ Nutrient } & \multicolumn{4}{|c|}{ Basic education } & \multirow[b]{3}{*}{$P^{*}$} \\
\hline & \multicolumn{2}{|c|}{$\begin{array}{l}\text { Less than high } \\
\text { school ( } n \text { 337) }\end{array}$} & \multicolumn{2}{|c|}{$\begin{array}{c}\text { High-school } \\
\text { degree (n 422) }\end{array}$} & \\
\hline & Mean & SD & Mean & SD & \\
\hline Energy (MJ) & $11 \cdot 7$ & $4 \cdot 0$ & $11 \cdot 7$ & $3 \cdot 1$ & 0.916 \\
\hline Energy (kcal) & 2793 & 959 & 2786 & 745 & 0.916 \\
\hline Protein (g/MJ) & $9 \cdot 4$ & $1 \cdot 2$ & $9 \cdot 6$ & $1 \cdot 3$ & 0.277 \\
\hline Carbohydrates (g/MJ) & $27 \cdot 9$ & $3 \cdot 0$ & $28 \cdot 3$ & $2 \cdot 8$ & 0.022 \\
\hline Sugar (g/MJ) & 14.9 & 3.5 & $14 \cdot 7$ & $3 \cdot 2$ & 0.672 \\
\hline Dietary fibre (g/MJ) & $2 \cdot 2$ & 0.7 & $2 \cdot 4$ & 0.6 & $<0.001$ \\
\hline Total fat (g/MJ) & $9 \cdot 6$ & $1 \cdot 3$ & $9 \cdot 3$ & $1 \cdot 2$ & 0.003 \\
\hline Saturated fatty acids (g/MJ) & 3.8 & 0.7 & 3.6 & 0.6 & $<0.001$ \\
\hline MUFA (g/MJ) & $3 \cdot 4$ & 0.5 & $3 \cdot 3$ & 0.5 & 0.006 \\
\hline PUFA (g/MJ) & 1.07 & 0.21 & $1 \cdot 11$ & 0.25 & 0.046 \\
\hline Total $n-3$ fatty acids (g/MJ) & 0.19 & 0.06 & 0.20 & 0.06 & 0.194 \\
\hline Total $n-6$ fatty acids (g/MJ) & 0.85 & 0.17 & 0.89 & 0.20 & 0.041 \\
\hline Essential fatty acids (g/MJ) & 0.99 & 0.21 & 1.02 & 0.24 & 0.081 \\
\hline
\end{tabular}

* By ANOVA; education level adjusted for mother's age.

The food-frequency method typically overestimates food consumption and nutrient intake, particularly of vegetables, but also the intake of energy and energy-yielding nutrients when compared with food records (Nelson \& Bingham, 1997). Although the energy-adjusted nutrient intakes would be more reliable with this kind of method, we present absolute intakes of vitamins and minerals in comparison with the recommendations. Subjects may distort their reported diet for several reasons, which can only be revealed by careful validation of the method (Nelson \& Bingham, 1997). The FFQ used in the present study is validated (Erkkola et al. 2001). The intake of foods and nutrients was higher as determined by FFQ than that assessed using food records. Pearson correlation coefficients for energy-adjusted nutrients ranged from 0.19 to 0.70 and, for foods, from 0.03 to 0.84 . On average, $70 \%$ of the foods and $69 \%$ of the nutrients fell into the same or adjacent quintiles, according to the FFQ and the food record. The validation study by Erkkola et al. (2001) suggests that the FFQ represents a useful tool for categorising pregnant women according to their dietary intake. Other FFQ validation studies have reported similar results in pregnant women (Greeley et al. 1992; Forsythe \& Gage, 1994; Robinson et al. 1996). The FFQ evaluated past diet, i.e. the women completed the questionnaire 3 months after

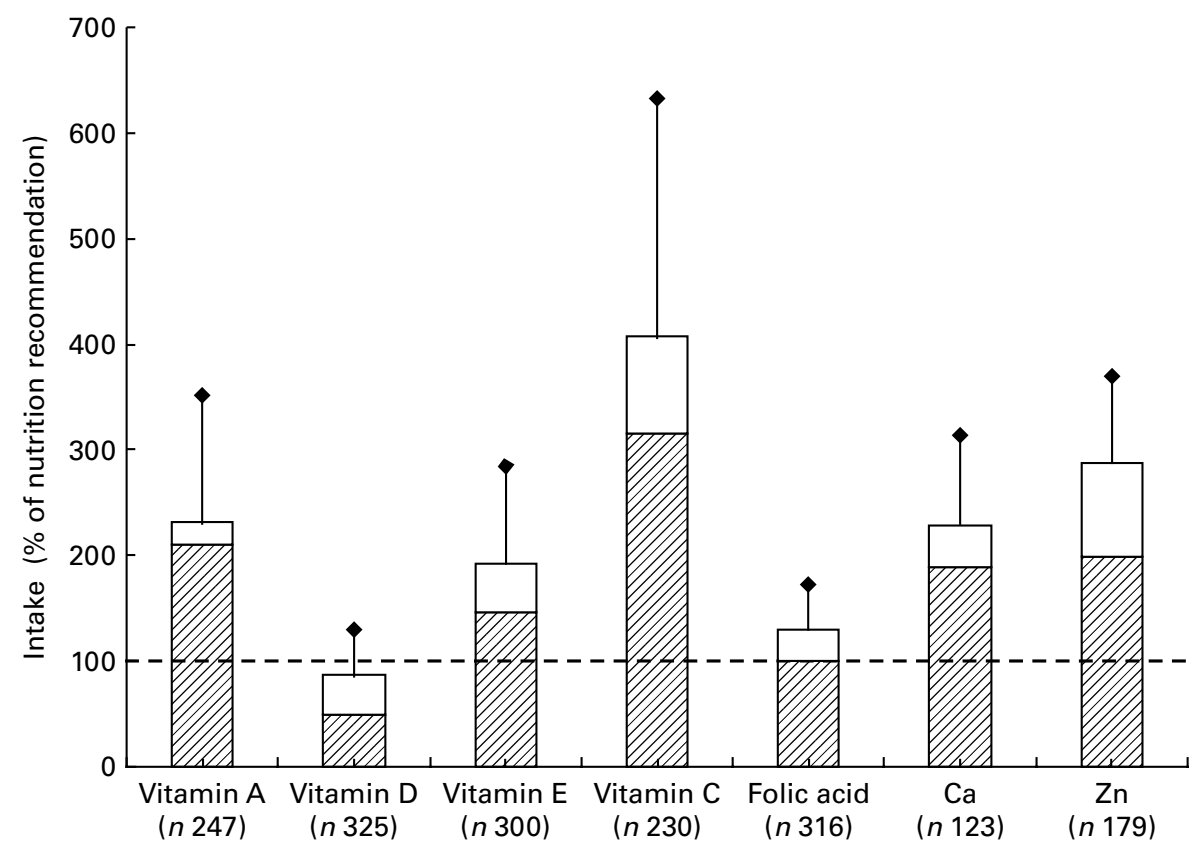

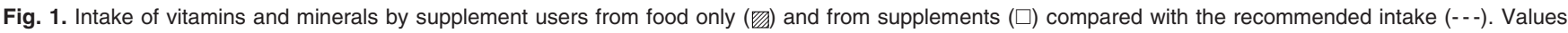
are means, with their standard errors represented by vertical bars. 
the eighth month of pregnancy. Earlier findings by Bunin et al. (2001) suggest that the diet during a past pregnancy is recalled rather well even after several years.

Age and education were positively associated with daily consumption of vegetables, fruits and berries in the present study. The same association was found earlier in US pregnant women (Bodnar \& Siega-Riz, 2002). Nevertheless, pregnant women consumed fewer servings of vegetables, fruits, berries, and fish than recommended. The consumption of these foods was low also in another study among pregnant US women (Borrud et al. 1993). The healthier food choices of the women with higher basic education were reflected in their higher intakes of dietary fibre, and of some vitamins. Type of fat in the diet was also closer to recommendations among the more educated women. Food intake in non-pregnant women using supplements has been characterised with ample use of vegetables and fruits (Elmståhl et al. 1996; Kaartinen et al. 1997; Lyle et al. 1998; Kirk et al. 1999), as seen also in the present study.

Our findings suggest that healthy food choices are rather common among Finnish pregnant women and that the increased nutrient requirements during pregnancy are mostly covered by a balanced diet. The use of nutrient supplements did not support the diet in every respect. The present study discovered both unnecessary nutrient supplementation and lack of relevant supplementation among Finnish pregnant women. Vitamin A was received, mostly in multivitamin supplements, although it is not recommended. The intake of vitamin D (food and supplementation) did not meet the dietary recommendation and almost half of the women received folic acid below recommendation. These results suggest that the proper assessment of pregnant women's dietary habits is important for targeted counselling and more precise advice on supplement use in well-women clinics.

\section{Acknowledgements}

We are grateful to all the mothers, study nurses and research scientists who took part in the present study. The DIPP Nutrition study was supported by the Academy of Finland, the Finnish Diabetes Association, the Finnish Diabetes Research Foundation, the Finnish Paediatric Research Foundation, the Häme Foundation of the Finnish Culture Fund, the Juho Vainio Foundation, the Medical Research Fund of Tampere University Hospital, the Yrjo Jahnsson Foundation and the Alma and K.A. Snellman Foundation. The DIPP Core study was supported by Special Public Grants for Medical Research at the participating university hospitals, the Academy of Finland (grants 63672, 79685, 79686, 80846, 201988, 210632), the Juvenile Diabetes Research Foundation International (grants 197032 and 4-1998-274), the Novo Nordisk Foundation and EU Biomed 2 (BMH4-CT98-3314).

\section{References}

Advisory Committee of Government (1998) Finnish Nutrition Recommendations (publication in Finnish). Helsinki: Edita.

Advisory Committee of Government (2005) Finnish Nutrition Recommendations - Diet and physical activity in balance. Helsinki: Edita.
Andersson AS (2001) Symposium on nutritional adaptation to pregnancy and lactation: pregnancy as a time for dietary change? Proc Nutr Soc 60, 497-504.

Berg MJ, van Dyke DC, Chenard C, Niebyl JR, Hirankarn S \& Bendich A (2001) Folate, zinc, and vitamin $\mathrm{B}_{12}$ intake during pregnancy and postpartum. J Am Diet Assoc 101, 242-245.

Bodnar LM \& Siega-Riz AM (2002) A diet quality index for pregnancy detects variation in diet and differences by sociodemographic factors. Public Health Nutr 5, 801-809.

Borrud LG, Krebs-Smith SM, Friedman L \& Guenther PM (1993) Food and nutrient intakes of pregnant and lactating women in the United States. J Nutr Educ 4, 176-185.

Bunin GR, Gyllstrom ME, Brown JE, Kahn EB \& Kushi LH (2001) Recall of diet during past pregnancy. Am J Epidemiol 154, 1136-1142.

Connor WE, Lowensohn R \& Hatcher L (1996) Increaced docosahexaenoic acid levels in human newborn infants by administration of sardines and fish oil during pregnancy. Lipids 31, S183-S187.

Elmståhl S, Wallström P, Berglund G, Janson L, Johansson U \& Larsson SA (1996) The use of dietary supplements in relation to dietary habits in a Swedish middle-aged population. Scand J Nutr 38, 94-97.

Erkkola M, Karppinen M, Järvinen A, Knip M \& Virtanen SM (1998) Folate, vitamin D, and iron intakes are low among pregnant Finnish women. Eur J Clin Nutr 52, 742-748.

Erkkola M, Karppinen M, Javanainen J, Räsänen L, Knip M \& Virtanen SM (2001) Validity and reproducibility of a food frequency questionnaire for pregnant Finnish women. Am J Epidemiol 154, 466-476.

Ervin RB, Wright JD \& Kennedy-Stephenson J (1999) Use of dietary supplements in the United States, 1988-94. Vital Health Stat 11, $1-14$.

Forsythe HE \& Gage B (1994) Use of a multicultural food-frequency questionnaire with pregnant and lactating women. Am J Clin Nutr 59, S203-S206.

Godfrey KM \& Barker DJP (1995) Maternal nutrition in relation to fetal and placental growth. Eur J Obstet Gynecol Reprod Biol 61, 15-22.

Greeley S, Storbakken L \& Mael R (1992) Use of a modified food frequency questionnaire during pregnancy. J Am Coll Nutr 11, $728-734$.

Hasunen K, Kalavainen M \& Keinonen H (1997) Lapsi, perhe ja ruoka. Dietary Recommendations for Children aged 0-5 and Pregnant and Lactating Women (publication in Finnish). Helsinki: Ministry of Social Affairs and Health.

Helakorpi S, Uutela A \& Prättälä R (1999) Health Behaviour Among Finnish Adult Population (publication in Finnish). Helsinki: National Public Health Institute.

Kaartinen P, Ovaskainen ML \& Pietinen P (1997) The use of dietary supplements among Finnish adults. Scand J Nutr 41, 13-17.

Kara R (1978) Food Consumption in Lactating Mothers in Helsinki and Effect of Trace Nutrients in Milk Composition (in Finnish). Masters Thesis, Department of Nutrition, University of Helsinki.

Kirk SF, Cade JE, Barrett JH \& Conner M (1999) Diet and lifestyle characteristics associated with dietary supplement use in women. Public Health Nutr 2, 69-73.

Lyle BJ, Mares-Perlman JA, Klein BE, Klein R \& Greger JL (1998) Supplement users differ from nonusers in demographic, lifestyle, dietary and health characteristics. J Nutr 128, 2355-2362.

Männistö S, Ovaskainen M \& Tapanainen L (2003) Finnravinto 2002 - Study. National Public Health Institute B3/2003. Helsinki: National Public Health Institute.

Mathews F, Yudkin P, Smith RF \& Neil A (2000) Nutrient intake during pregnancy: the influence of smoking and age. $J$ Epidemiol Community Health 54, 17-23.

Nelson M \& Bingham SA (1997) Assessment of food consumption and nutrient intake. In Design Concepts in Nutritional Epidemiology, 
pp. 123-169 [BM Margetts and M Nelson, editors]. Oxford, UK: Oxford University Press.

Nordic Working Group on Diet and Nutrition (1996) Nordic Nutrition Recommendations. Scand J Nutr 40, 161-165.

Ortega RM, Gaspar MJ \& Moreiras O (1994) Dietary assessment of a pregnant Spanish women group. Int J Vit Nutr Res 64, $130-134$.

Piirainen T, Isolauri E, Huurre A, Hoppu U \& Laitinen K (2004) Dietary and health counselling in well-women (WW) and well-baby (WB) clinics in Finland (article in Finnish). Suomen Lääkärilehti 59, 2047-2053.

Robinson S, Godfrey K, Osmond C, Cox V \& Barker D (1996) Evaluation of a food frequency questionnaire used to assess nutrient intakes in pregnant women. Eur J Clin Nutr 50, 302-308.

Rogers I \& Emmett P (1998) Diet during pregnancy in a population of pregnant women in South West England - Avon Longitudinal
Study of Pregnancy and Childhood (ALSPAC). Eur J Clin Nutr 52, 246-250.

Social and Health Ministry (1995) Folic Acid and Neural Tube Defect. Recommendations from the Expert Group (in Finnish). Helsinki: Ministry of Health and Social Affairs.

Timbo B, Altekruse S, Hyman F, Klontz K \& Tollefson L (1994) Vitamin and mineral supplementation during pregnancy. Mil Med 159, 654-658.

Voyles LM, Turner RE, Lukowski MJ \& Langkamp-Henken B (2000) High levels of retinol intake during the first trimester of pregnancy result from use of over-the-counter vitamin/mineral supplements. $J$ Am Diet Assoc 100, 1068-1070.

Zeghoud F, Vervel C, Guillozo H, Walrant-Debray O, Boutignon H \& Garabedian M (1997) Subclinical vitamin D deficiency in neonates: definition and response to vitamin D supplements. Am J Clin Nutr 65, 771-778. 